\title{
Gastrointestinal Microbiome: Novel Paradigm Proposed in the Treatment of Autism Spectrum Disorder Associated Social Behavioral Symptoms in Two Rodent Models
}

Kitti Mintál ( $\square$ kitti.mintal@aok.pte.hu )

University of Pécs

Attila Toth

University of Pécs

Edina Hormay

University of Pécs

Anita Kovács

University of Pécs

Kristóf László

University of Pécs

Anita Bufa

University of Pécs

Tamás Marosvölgyi

University of Pécs

Béla Kocsis

University of Pécs

Adorján Varga

University of Pécs

Zoltán Vizvári

University of Pécs

Renáta Cserjési

Eötvös Loránd University

László Péczely

University of Pécs

Tamás Ollmann

University of Pécs

László Lénárd

University of Pécs

Zoltán Karádi

University of Pécs 
Research Article

\section{Keywords:}

Posted Date: January 20th, 2022

DOl: https://doi.org/10.21203/rs.3.rs-1235045/v1

License: (c) (1) This work is licensed under a Creative Commons Attribution 4.0 International License. Read Full License 


\section{Abstract}

The prevalence of autism spectrum disorder (ASD) has rapidly increased in the past decades, and several studies report about the escalating use of antibiotics and the consequent disruption of the gastrointestinal microbiome leading to the development of neurobehavioral symptoms resembling to those of ASD. The primary purpose of this study was to investigate whether depletion of the gastrointestinal microbiome via antibiotics treatment could induce ASD-like behavioral symptoms in adulthood. To reliably evaluate that, validated valproic acid (VPA) ASD animal model was introduced. At last, we intended to demonstrate the assessed potential benefits of a probiotic mixture (PM) developed by our research team. Male Wistar rats were used to create antibiotics treated; antibiotics and PM treated; PM treated, VPA treated; VPA and PM treated; and control groups. In all investigations we focused on social behavioral disturbances. Antibioticsinduced microbiome alterations during adulthood triggered severe deficits in social behavior similar to those observed in the VPA model. Furthermore, it is highlighted that our PM proved to attenuate both the antibiotics- and the VPA-generated antisocial behavioral symptoms. The present findings underline potential capacity of our PM to improve social behavioral alterations thus, indicate its promising therapeutic power to attenuate the social-affective disturbances of ASD.

\section{Introduction}

Autism spectrum disorder (ASD) is a complex neurodevelopmental disorder characterized by impaired social interactions and communication along with the presence of disturbances of repetitive stereotyped behaviors 1,2. Eventually, difficulties with social interactions have been supposed to be the major deficits and these most severe symptoms of the illness persist across the lifespan ${ }^{3-6}$. Therefore, one of the key elements of the therapeutic approaches is the development and evaluation of interventions to strengthen the social skills of the patients ${ }^{6}$. The current solutions are limited to social skills training ${ }^{7}$. However, despite all these strategies, there are no recognized pharmacological treatments to cure the core features of ASD.

Nevertheless, there are studies where sulforaphane, oxytocin or arginine-vasopressin treatments were able to improve the general condition of patients ${ }^{8-10}$. Along with these developments valid animal models are required to test the new therapeutic strategies aiming to improve the core features of ASD. These models also proved to be useful to examine the morphological effects of specific causal factors on characteristic neuropathology of the disease ${ }^{11}$. Ablation of associated genes or the use of some chemicals in animals can result in a behavioral phenotype reminiscent of ASD, with specific impairments in social interaction, communication and repetitive behaviors ${ }^{12-14}$. The valproic acid (VPA) animal model is one of the most frequently studied rodent models of ASD in which a single prenatal exposure to VPA in rodents results in lifelong behavioral disturbances and differentially alters morphological parameters of hippocampal regions 13,15-17. This ASD animal model appears to possess all elements of a relevant and capable model, namely, face, construct, and predictive validity, and, therefore, it can represent an important strategic tool for developing novel therapeutic approaches ${ }^{15,18,19}$.

Epidemiological studies have reported a gradual increase of the prevalence of ASD in the last decades ${ }^{20}$. This continuous rise is suggested to appear due to the increasing contamination by environmental factors 
such as toxins, heavy metals, chemicals, maternal infection, various pathogens, and, recently the escalating use of antibiotics has also been proposed as a causal factor $21-25$. Investigations over the last few years suggested that broad-spectrum antibiotics exposure slightly increases the risk of autism in early childhood 26,27 , however, the currently available research data pool does not substantiate the notion that either the preor post-natal antibiotics exposure is really one of the risk factors for ASD ${ }^{23}$. Nevertheless, broad-spectrum antibiotics treatments in animal studies can provide another useful way to examine the relationship between the effects of environmental factors, such as antibiotics exposure, and the multiple symptomatology of ASD 23. Furthermore, it has also been demonstrated that the antibiotics induced manipulation of complex composition of the intestinal microbiota can ultimately affect brain functions leading to behavioral alterations, through the microbiome-gut-brain axis ${ }^{23,27-29}$. Certain antibiotics, their definite dosages, during assigned perinatal stages appear to affect social behavior ${ }^{29}$. In adulthood, the effect of antibiotics treatment on social behavior is less studied, but still there are some investigations that provided evidence for that the usage of antibiotics can elicit behavioral changes ${ }^{29,30}$. The employment of probiotics and prebiotics also modulates the composition of the gastrointestinal (GI) microbiome, and recently, probiotics are not only utilized to just reduce unwanted aftereffects following the antibiotics treatments ${ }^{31}$, but some beneficial microbe types are also applied to improve several peripherally and/or centrally controlled functions. It is worth noting that such medications are successfully used to improve symptoms of several neurobiologically determined disease-like conditions, psychiatric disorders, depression, etc. ${ }^{32,33}$. Furthermore, short chain fatty acids (SCFAs), the main microbiome metabolites, produced by bacterial fermentation, can directly or indirectly affect microbiome-gut-brain axis and their dose might be critical in determining the effects on behavioral and psychophysiological processes ${ }^{34}$. For all that, the use of antibiotics and distinct probiotics with well-defined characteristics can modulate the gut microbiota, thus, provide us a tool to examine the relationship between ASD associated symptoms and the functioning of microbiome-gut-brain axis.

The present study aimed to investigate whether chronic antibiotics treatment in adult rats could cause social behavioral abnormalities similar to those described in the ASD. Accordingly, we adapted the VPA animal model of ASD to evaluate and compare these illness associated characteristic social behavioral phenomena in adulthood. Another further goal of this study was to treat the rats having antibiotics-induced behavioral abnormalities by a probiotic mixture (PM) designed by our research team. Our assumption was that the PM could reduce the pathological behavioral patterns through the beneficial changes induced in the GI microbiome which could be a possible new therapeutic approach to cure social behavioral symptoms.

\section{Methods}

\section{Animals}

In the present study, in total, 60 male Wistar laboratory rats (antibiotics treated groups 40, valproic acid treated groups 20) were used (10 weeks old at start of treatments). All animal experiments were conducted according to federal and local ethical guidelines, and the protocols were approved by the National Scientific Ethical Committee on Animal Experimentation of Hungary (BA02/2000-15/2020 and BA02/2000-16/2020, 
Pécs University, Medical School; Hungarian Government Decree, 40/2013. (II. 14.); NIH Guidelines, 1997; European Community Council Directive 86/609/EEC 1986, 2006; European Directive 2010/63/EU of the European Parliament). The present study is reported in accordance with ARRIVE guidelines. The animals were kept individually in a light and temperature-controlled room (12:12 h light-dark cycle; $21 \pm 2{ }^{\circ} \mathrm{C}$; humidity 55-60\%). To exclude sex as an additional independent variable, only male rats were used in this study. All experimental groups received ad libitum the same laboratory food pellets (LT/R standard rodent food pellet, Innovo Kft, Isaszeg, Hungary) and tap water.

\section{Treatments of the antibiotics groups}

Animals have been divided randomly into four groups: 1. Control group (control); 2. Antibiotics treated group $(A B x) ; 3$. Antibiotics and probiotic treated group (ABx+probiotic); 4. Probiotic treated group (probiotic) (Figure 1). To effectively deplete the gut microbiota the rats of the antibiotics treated groups received broadspectrum antibiotics mixture for 4 weeks in adult animals (10 weeks old at the start of treatment). The antibiotics cocktail was dissolved in their drinking water to avoid any chronic stress-induced adverse effects. The antibiotics mixture was chosen based on published protocols ${ }^{30}[30]^{30}$, consisted of ampicillin $(1 \mathrm{~g} / \mathrm{L})$, vancomycin (500 mg/L), ciprofloxacin $\mathrm{HCl}(20 \mathrm{mg} / \mathrm{L})$, imipenem $(250 \mathrm{mg} / \mathrm{L})$ and metronidazole $(1 \mathrm{~g} / \mathrm{L})$. This antibiotics cocktail was replaced by freshly made cocktail every 3 days. Probiotic treated and control animals received tap water in the absence of any antibiotics which was also changed every 3 days. (Pilot experiment was conducted $(n=8)$ to exclude possible behavior changes due to antibiotics-induced intestinal discomfort or pain, detailed in the Supplementary Information and Supplementary Table S1) After this antibiotics exposure in the ABx+probiotic group, and the probiotic group were given our PM of specified $\mathrm{cfu} / \mathrm{d}$ (colony forming units/day), oral gavage every day for 2 weeks. Our specific PM contained four beneficial bacterial species (Lactobacillus spp., Bifidobacterium spp.) and this PM is a know-how under the license of the University of Pécs. Throughout the whole experiment water and food consumption were measured every day and the animals' weights were measured every 3 days. Fresh faecal pellets were collected every week for monitoring the alterations of the SCFAs. Behavioral tests started after the treatments.

\section{Treatments of the valproic acid groups}

The valproic acid animal model has been generated as previously described ${ }^{35}$. Male and female Wistar rats were mated one overnight, and the morning when a vaginal plug was found was designated as the first day of gestation. Pregnant female rats received a single intraperitoneal injection of $500 \mathrm{mg} / \mathrm{bwkg}$ valproate (Sigma-Aldrich; P4543) dissolved in physiological saline at a concentration of $250 \mathrm{mg} / \mathrm{ml}$ on the 12.5th day of gestation, and control females were injected with physiological saline at the same time. Valproate-treated females were healthy individuals and the number of animals per litter was approximately 25\% lower in VPA compared to control dams. Females were housed individually and were allowed to raise their own litters. Male offsprings, when reached 8 weeks, were then separated and they were kept individually throughout the experiment. These animals have been divided randomly into two groups: probiotic treated valproate group (P-VPA); 2. control valproate group (C-VPA) (Figure 1). The P-VPA group were given the above described PM every day for 2 weeks. Water and food consumption were measured every day and the animals' weights 
were measured every 3 days during the experimental period. Fresh faecal pellets were collected every week. Behavioral tests were conducted in the same sequence in every group of animals. All 60 animals ( $n=10 /$ group) completed each behavioral test and their accompanying tissue samples were used for further analyses.

\section{Three chambered social interaction test}

A three chambered social interaction task was used to assess social behavior. The protocol was adapted from a previously published article ${ }^{36}$ The apparatus $(150 \times 40 \times 40 \mathrm{~cm})$ was divided into three chambers: the nonsocial zone $(60 \times 40 \mathrm{~cm})$, the social zone $(60 \times 40 \mathrm{~cm})$ and the centre $(30 \times 40 \mathrm{~cm})$. The non-social and the social zone contained small circular wire cages with a diameter of $18 \mathrm{~cm}$. The testing arena was cleaned with $1 \%$ Incidin after each testing trials. Before the sociability task experimental rats immediately were given a habituation session. They were placed into the centre of the apparatus, where they were allowed to explore it for 10 minutes. Right away this habituation session test animals were locked in the centre zone for 3 minutes, while a stranger rat of the same strain and sex was placed into one of the two rat cages in the side chambers. Therefore, one of the side chambers which contained a stranger rat would be the social zone and the other chamber, where the cage remained empty would be the non-social zone. Test animals had no previous interaction with stranger animals for this task and the placement of the stranger rat was randomized and counterbalanced. Following this 3 minutes centre zone locking, animals were provided 10 minutes to freely explore the whole apparatus. The entire experimental period was recorded and analyzed by recorded camera shots processed by Noldus EthoVison System (Noldus Information Technology, The Netherlands). We measured the total distance moved, time spent in the side chambers, and during the sociability task latencies to first entry to the side chambers were also determined. Furthermore, direct interactions with either the stranger rat- or empty cages were counted. All types of exploratory behavior were noted, and the sociability index (time spent in the social zone - time spent in the non-social zone) / (time spent in the social zone + time spent in the non-social zone) was also used to indicate a preference to interact with or avoid the stranger rat.

\section{Short chain fatty acids analysis}

We used the protocol of Wall et al. ${ }^{37}$ with modification on the internal standard to measure SCFAs. $100 \mathrm{mg}$ of faecal samples were weighted out and vortex-mixed with $1 \mathrm{ml}$ of distilled water. After standing for $10 \mathrm{~min}$ at room temperature, $100 \mu \mathrm{l}(2 \mathrm{mmol} / \mathrm{L})$ Heptanoic acid (Sigma-Aldrich; 43858) as an internal standard was added to them and the samples were centrifuged at $10.000 \mathrm{rpm}$ for $5 \mathrm{~min}$. Then supernatant fluids were collected and filtered before being transferred to the vials. Standard solutions containing $10 \mathrm{mmol} / \mathrm{L}, 7.5$ $\mathrm{mmol} / \mathrm{L}, 5 \mathrm{mmol} / \mathrm{L}, 2.5 \mathrm{mmol} / \mathrm{L}$ and $0.5 \mathrm{mmol} / \mathrm{L}$ of acetic acid (Sigma-Aldrich; A6283), propionic acid (Sigma-Aldrich; 94425) and butyric acid (Sigma-Aldrich; 19215), respectively, were used for calibration. The concentration of SCFAs analyses were carried out on an Agilent $6890 \mathrm{~N}$ gas chromatograph with a 5975 mass spectrometer detector (Agilent, Santa Clara, CA, USA) fitted with a HP-INNOWAX column (30 m x 0.25 $\mathrm{mm} \times 0.25 \mu \mathrm{m}$; Agilent). Helium was used as the carrier gas at a flow rate of $1.5 \mathrm{~mL} / \mathrm{min}$. The initial oven temperature was $80^{\circ} \mathrm{C}$ held for $1 \mathrm{~min}$ and ramped up to $200^{\circ} \mathrm{C}$ at $20^{\circ} \mathrm{C} / \mathrm{min}$ and held for $2 \mathrm{~min}$. The injection port was adjusted at $250^{\circ} \mathrm{C}$ and split injection mode was used, the injection ratio was $20: 1$. The 
injection volume was $1 \mu \mathrm{L}$. The interface temperature was maintained at $250^{\circ} \mathrm{C}$, the source temperature and the quadrupole mass analyzer temperature were set at $230^{\circ} \mathrm{C}$ and $150{ }^{\circ} \mathrm{C}$. The solvent delay was 3 min. The mass spectrometer was operated at $70 \mathrm{eV}$ in the electron impact (EI) mode and the scanned mass range was 50-300 amu.

\section{Histology}

At the end of behavioral experiments animals were euthanized and transcardially perfused with physiological saline followed by $4 \%$ formalin solution. The brains of 6 animals/ groups were fixed in $4 \%$ formalin, afterwards they were cut into $40 \mu \mathrm{m}$ sections containing the hippocampus. The sections were stained using Cresyl Violet staining. Briefly, they were immersed in 70 and $50 \%$ ethanol and double distilled water for $5 \mathrm{~min}$. The slides were then stained for $7 \mathrm{~min}$ in $0.5 \%$ cresyl violet solution, and then briefly rinsed in distilled water. They were then dehydrated in 70\% ethanol with 10 drops of $100 \%$ acetic acid, 70, 90, double $90 \%$ ethanol, double 1-propanol for 1 minute each. The slices were placed in 1:1 mixed 1-propanol and xylene for $5 \mathrm{~min}$ and then in xylene for overnight and then coversliped. The open-source imageprocessing software package ImageJ $(\mathrm{NIH})$ was used for image analysis. The diameter of the hippocampal regions (subiculum, CA1, CA2, CA3, dentate gyrus) of the selected section (bregma -3.6 - 3.8 mm) were measured.

\section{Statistics}

In the three chamber social interaction test the stranger- and empty cage latency and the social index did not pass through normality- and homogeneity test, in these cases non-parametric Kruskal-Wallis test was used to analyze group differences between C-VPA, P-VPA, control, ABx, ABx+probiotic and probiotic treated groups, and if a difference was found to be significant, pair-wise comparison was done using the MannWhitney U-test. Data were presented as median (interquartile range [IQR]). For the other comparisons in the three chamber social interaction test, body weight, food- and water consumptions among the groups parametric one-way ANOVA was used and Post-hoc group mean comparisons were conducted using Tukey's post hoc test. All of these data were presented as mean \pm standard error of the mean (SEM). The analysis of the SCFAs was completed by Friedman test, and the results were demonstrated as median (IQR). The data of histological measurements did not have normal distribution, therefore, Kruskal-Wallis test and MannWhitney U-test were conducted. Significance was denoted with selection of a p-value of less than 0.05 . Statistical analyses were conducted using the statistical software package (IBM SPSS Statistics 22).

\section{Results}

\section{Body weight comparisons, food and water consumptions}

Prenatal valproic acid treatment, antibiotics and/or probiotic administration had no significant effect on body weight change compared to the control group (Supplementary Figure S1). Some of the animals receiving antibiotics had significantly decreased food- and water consumptions during the first period of antibiotics treatment, however, after this first one week period, food and water intakes of the animals were normalized and the treatments did not affect the consumptions (Supplementary Figure S1). 


\section{Effects of antibiotics- or valproic acid treatment on social behavior}

Latency to the first exploration of both the stranger rat and empty cage were analyzed. Although the treatment effects on latency to explore the social zone were non-significant, probiotic treated rats show a tendency to explore later the zone of the empty cage (Table 1).

The total time spent exploring the stranger rat or empty cage was also analyzed (Figure 2). C-VPA animals spent significantly less time in the social zone $(p=0.000)$ and more time in the non-social zone $(p=0.000)$. Similar to this group, antibiotics treated animals exploring either the stranger $(p=0.001)$ or empty cage $(p=$ 0.001 ) were significantly different from members of the other groups. While compared to the habituation session each group spent balanced time in the social- and in the non-social zone (data not shown).

The sociability index was also estimated to indicate a preference to the stranger rat. This index for the $A B x$ and the C-VPA rats was significantly lower than for the animals of the other groups $(p=0.009)$ : it reduced by approximately $70 \%$, compared to the other groups (Table 1 ).

Analysis of the frequency for which the social zone was explored in relation to the non-social zone (Figure 3 ) also revealed group differences. For the social zone, exploration frequency in the ABx+probiotic group deviated from the others: these animals had higher number of entrances to this zone than had the ABx-, $C$ VPA- $(p=0.035)$ and probiotic $(p=0.041)$ groups. Nevertheless, exploration frequency in the non-social zone of the groups did not show significant differences. Interactions with stranger animal and empty cage were overall calculated (Figure 4). We did not find any difference among the groups in the empty cage interaction, however, compared to individuals of the control and the probiotic groups, significantly less interactions were observed with the stranger rat in the ABx $(p=0.007 ; p=0.005)$ and C-VPA animals $(p=0.021 ; p=0.017)$, moreover, $A B x$ rats differed from the ABx+probiotic $(p=0.019)$ and P-VPA $(p=0.048)$ rats, too.

The total distance travelled did not show significant differences among the groups (Table 1). Furthermore, we also evaluated calculated stereotype behaviors, the results showing no significant differences in the examined rearing and grooming behaviors (Table 1).

\section{Concentration of the short chain fatty acids in relation to the treatments}

Concentrations of the SCFAs were analyzed in all groups before, during and after the treatments. Median (IQR) values of the concentrations of the SCFAs are given in Table 2. Significant differences were observed in all the three measured fatty acid concentration after the antibiotics treatment. Antibiotics significantly reduced SCFAs concentrations compared with the C-VPA $(p=0.000)$, P-VPA $(p=0.002), A B x+$ probiotic $(p=$ $0.033)$, probiotic $(p=0.007)$ and control $(p=0.006)$ groups (Table 2$)$. Additionally, acetic acid $(p=0.000)$, butyric acid $(p=0.000)$ and propionic acid $(p=0.006)$ concentrations were also diminished within the $A B x$ group (Figure 5). Associated to the probiotic treatment, SCFAs concentrations did not change significantly in case of the majority of groups (Table 2). However, for the ABx+probiotic treated animals, significant decrease $(p=0.003)$ was identified after the usage of antibiotics. It is worth noting that the probiotic treatment was able to restore this decrease to the original state (Figure 6). Compared within the $A B x+$ probiotic group, before and after both of the treatments, only the butyric acid concentration was 
significantly higher at the end of the treatments $(p=0.001)$ than before the interventions, but there were no differences in the acetic acid and propionic acid concentrations. Although, there were no significant changes in the butyric acid concentrations, there was a tendency for higher butyrate composition in the ABx+probiotic rats compared to animals of the other groups. Examination of the prenatal VPA exposed rats did not present significant differences among and within these animal groups.

\section{Histology}

At the end of behavioral experiments, after preparation of the brains, the diameter of the major hippocampal regions (subiculum, CA1, CA2, CA3, dentate gyrus) was compared among 6-6 animals / groups. Based on the results, diameter of the various hippocampal regions demonstrated extreme differences (Supplementary Table S2; Supplementary Figure S2), nevertheless, the thickness of each region also revealed remarkable alterations within the groups. Therefore, our histological data, at their present form, proved not to be correctly interpretable.

\section{Discussion}

The purpose of this study was to assess the impact of broad-spectrum antibiotics treatment on social behavior in adulthood. To our best knowledge, this report is the first one to demonstrate that chronic depletion of the gut microbiota in adulthood induces profoundly similar social behavioral abnormalities to those observed in animals of the VPA rat model of ASD. Furthermore, as it was supposed, after the antibiotics treatment, our PM was able to re-establish the normal social behavior. In addition to that our PM treatment was capable to markedly reduce the social abnormalities in the VPA animal model, it also appears that even distinct changes of the microbiome could result in remarkable changes in a completely developed brain. According to our present findings, these changes take place in a non-SCFA dependent way.

The instantaneous effect that the GI microbiome exerts on the social behavior has been studied primarily with germ free animals (total lack of microbes) and with certain antibiotic treatments on rodents in their early pre-or post-natal period of life ${ }^{29}$. These studies primarily revealed impairments of sociability. Furthermore, colonizing germ free mice with normal faecal microbiota was able to restore the sociability defects. Based on these results, it is reasonable to propose that the gut microbiota is involved in integratory processes of social development ${ }^{38,39}$. Despite all these facts the effect of broad-spectrum antibiotics treatment on social behavior is less studied in adulthood. One of the fundamental findings of the current study highlights that the antibiotics induced bacterial depletion in adulthood can elicit the same type deficits of the social interaction as those observed in the VPA autism rat model. The sociability index results, indicating a preference to the stranger rat, presented that rats of the C-VPA- and ABx groups display social interaction deficits. These findings suggest that chronic broad-spectrum antibiotics treatment in adulthood negatively affects the social behavior, moreover, it seems as if these deficits were the same type as those we could identify in the VPA rat model of ASD. This finding appears to support the notion that the antibioticsmodified microbiome can act as a causal agent and a risk factor in the development of ASD $23,26,40$. Despite these social abnormalities, group differences were not found in the total distance travelled and in the latencies to explore the stranger cage. Otherwise, a pilot experiment with $\mathrm{LiCl}$ induced visceral illness was 
not able to result in reduced sociability what we detected in the microbiome depleted ABx rats. These results suggest that impaired sociability is likely cannot be due to the general consequence of visceral discomfort or pain in these animals. The above data underline the importance of disruption of the healthy balance of microbial community and its specific impact on the microbiome-gut-brain axis that leads to the deficits of social behavior regardless of whether visceral discomfort exists or not.

It is established that antibiotics- or VPA treatments interfere with the physiology of the animals disparate ways. In the former case, antibiotics administration strongly depletes gut microbiota, and thus, triggers alterations of the microbiome-gut-brain axis that ultimately lead to behavioral (as well as molecular) deviations ${ }^{30,41}$. In the latter case, prenatal VPA exposure was shown to modify histone deacetylase activity, to alter gamma-aminobutyric acid or Wnt (wingless-type) signaling, and/or to disturb axonal remodeling in the developing neurons ${ }^{16,19,42}$. These mechanisms can provoke dysfunctions in several brain areas, generating morphological changes, especially in cortical and hippocampal regions ${ }^{16,43}$. Nevertheless, our histological analysis revealed very high variability within and among the animals, hence, we could not verify that such differences (e.g. in the thickness of hippocampal regions) indeed exist between the VPA treated and other groups. Even though the treatments appeared to act divergent ways, we still noticed similar social behavioral alterations between these groups. Therefore, to more precisely explore the role of the $\mathrm{GI}$ microbiome in the development of ASD symptoms, we approached this issue from another direction and introduced a probiotic therapy to interfere these treatments. Previous studies have shown that application of certain probiotics have beneficial effects on antibiotics-induced physiological and psychological abnormalities ${ }^{44,45}$. Moreover, as different gut microbial community was found in ASD patients in contrast to the healthy individuals, researchers attempted to modify the gut microbiome via probiotics and some results indicate beneficial effects on both behavioral and GI manifestations of ASD ${ }^{46-49}$. In addition, VPA rat model not just imitate ASD symptoms, it also has a transgenerational impact on the gut microbiota ${ }^{50-52}$. Nevertheless, limited research is available where probiotics are investigated in the VPA animal model as they could be effective therapy, only one study has recently revealed that VPA induced behavioral alterations could be reduced by daily supplementation with Lactobacillus strains ${ }^{53}$. In our present study, it is demonstrated for the first time that specified PM can be a potential novel approach to improve social behavioral alterations both in the VPA- or antibiotics induced animal model. Our PM was able to improve the preference to the stranger rat in both of the C-VPA and ABx treated groups, thus antisocial behavior was reduced. Moreover, the present results demonstrated that the same behavior can be seen in the C-VPA and $A B x$ treated groups as it appeared in the control group. However, the PM itself was not able to significantly change all aspects of the behavior, only in the frequency of the social zone exploration was detected notable difference between the probiotic and the control rats, but this was presumably generated by the fact that probiotic treated animals spent more time in the social zone once they entered there.

Despite the fact that both models developed by different mechanisms, quite similar social behavioral abnormalities were noticed, additionally, our PM was able to reconstruct these behavioral phenomena just as they appear in the control rats. Regarding these consequences, it is suggested that in both models the protective effects of the probiotic treatment get exerted in the same way. A series of studies have described that SCFAs improve the gut health, regulate immune mechanisms and they may possess neuroactive 
properties ${ }^{34,54-57}$. However, findings from ASD human studies on the associations among the three main SCFAs have proved to be divergent ${ }^{58-60}$. At the same time, in rodent models, the administration of propionic acid could produce behavioral changes closely resembling those found in ASD ${ }^{61}$, and in the VPA autism model changes of the SCFAs concentrations were also observed ${ }^{50}$. In spite of all these, the analysis of the main SCFAs did not show significant differences between the VPA treated and the control animals, and, after the probiotic therapy, there were also no remarkable effects seen in the SCFAs productions. Nevertheless, it is clear that the antibiotics treatment itself significantly decreases the levels of all the examined SCFAs, referring to the highly decreased total amount of the microbiome in these animals. In spite of the fact that the PM considerably elevated the concentration of the SCFAs after the antibiotics treatment, we did not reveal extreme alterations among the groups after the end of the treatments. However, it is reasonable to suppose that the probiotic impact would be necessarily stronger after the antibiotics administration than in case of challenging the compact, untreated microbiome community. The present results undeniably indicate that the change of concentration of the main SCFAs cannot be the sole causal factor that determines how the PM exerts its positive impact on the social behavior.

Increasing amount of data support the consideration that the manifested inflammation and metabolic patterns are quite comparable in both investigated animal models ${ }^{62,63}$. While, in the antibiotics-treated rat model, the inflammatory processes and the serotonergic system appear to be linked to the gut dysbiosis $30,64,65$, in the VPA animal model the elevated pro-inflammatory state, chronic glial activation and disturbance of the serotonergic system are caused by impact of the VPA to the developing brain $65-68$. Therefore, these observations encourage us to maintain the presumption that our PM made an effect on the serotonergic system without the mediation of the alterations of the SCFAs, thus, providing us the opportunity to hypothesize this to be the common way how the probiotic formulation can re-establish the behavioral alterations. It could occur in a way that modification and reduction of the inflammatory processes (diminishing the gut permeability) altogether with the altered microbiome could interact and alter the serotonergic system ${ }^{69-73}$. Since GI microbiota can directly or indirectly influence the tryptophan availability and the serotonin synthesis, thus, it ultimately influences the regulation of the kynurenine pathway. This pathway controls the production of the neuroprotective kynurenic acid (N-methyl-d-aspartate (NMDA) receptor antagonist) and that of the neurotoxic quinolinic acid (NMDA receptor agonist) ${ }^{72}$. So, the modulations of this system could lead to altered expression levels of NMDA ${ }^{72,74,75}$. It has been demonstrated that antibiotics could also alter NMDA receptor subunit expressions ${ }^{76}$. Recent studies have also identified that post-natal VPA treatment enhanced NMDA receptor functioning in the brain which may indicate a compensatory homeostasis with the presence of an excitatory/inhibitory imbalance during development. In subsequent experiments, when using pharmacological suppression therapy or NMDA receptor antagonists, they were able to normalize social deficits $50,66,77,78$. These results highlight the impact of these transcriptional modifications which could be the last elements in the way how our probiotic could restore the antisocial behavior, since NMDA receptors play an essential role in complex cognitive and social behavioral processes ${ }^{79,80}$. Nevertheless, further studies are needed to measure constituent elements of inflammatory processes, metabolic patterns and NMDA receptor expression levels in both animal models along with measuring these values after the probiotic treatment. Furthermore, additional investigations are 
necessary to examine changes of other minor SCFAs, as well as to apply other behavioral tests to explore wider ranges of behavioral alterations. Indeed, future studies should also clarify whether the 2 weeks of our PM exposure ensures only shorter, temporary or lasting effects on the social behavior. Furthermore, future studies are expected to reinforce the therapeutic efficacy of our PM on the ASD.

Taken together, our data confirm that broad-spectrum antibiotics treatment during adulthood can induce antisocial behavior similar to that observed in the VPA autism animal model. The current study suggests that the homeostatic balance of the GI microbiome has a profound effect on the social behavior. To our best knowledge this study is among the first ones to demonstrate that specific probiotic mixture can restore the same type of antisocial behavioral phenomena in these two disparate animal models, developed by distinct mechanisms. Based on the present data, this probiotic formulation targets a common pathway with a nonSCFA dependent manner. Overall, this study provides preliminary evidence for that GI microbiome, more specifically some bacterial combinations, appears to have therapeutic value to cure or at least attenuate the illness of social behavior, and thus, to get prepared to act as a proper therapeutic agent to eliminate symptoms of antisocial behavior in the ASD.

\section{Declarations}

\section{Data availability}

All data generated or analysed during this study are included in this published article [and its supplementary information files].

\section{Acknowledgments}

This work was supported by Proof of Principle PTE/101413-1/2019, PTE ÁOK KA 2013/34039/1; EFOP3.6.1-16-2016-00004; EFOP-VEKOP; TKP2, PTE-ÁOK-PD-2018-10-2017-09, ÚNKP-20-5-PTE-480 New National Excellence Program of the Ministry for Innovation and Technology and PTE ÁOK KA-2020-06. The authors express their grateful thanks to Fanni Géczi, Ildikó Fuchs, Ágnes Gonda, Nina Győrfi, Mátyás Wahr, Erika Gáspárné Bak, Erika Kvak, Ákos Klonga and Ferenc Wilhelm for their invaluable technical assistance.

\section{Author contributions}

K.M., A.T., Z. K made the study design and conceptualization. K. M. wrote the manuscript. A. T. and Z. K. supervised the research. K. L. provided the VPA animal model. K. M., A. K., E. H., T. O. conducted the behavior experiments. B. K. and A. V. produced the probiotic mixture. A. B., T. M., K. M. performed the SCFA analysis. K. M. E. H. carried out the histological staining and evaluations. R. C. provided intellectual support for the ASD model and the behavioral experiment. M. K., Z. V., L.P. organized the experimental data and conducted the statistical analyses. Z. K. and L. L. critically reviewed the manuscript. All authors have read and agreed to the published version of the manuscript.

\section{Additional information}

Supplementary Information 


\section{Competing interests}

The authors report no biomedical financial interests or potential conflict of interest

Correspondence and requests for materials should be addressed to K.M.

Reprints and permissions information is available at www.nature.com/reprints.

\section{References}

1. Sharma, S. R., Gonda, X. \& Tarazi, F. I. Autism Spectrum Disorder: Classification, diagnosis and therapy. Pharmacol Ther 190, 91-104, doi:10.1016/j.pharmthera.2018.05.007 (2018).

2. Lord, C., Elsabbagh, M., Baird, G. \& Veenstra-Vanderweele, J. Autism spectrum disorder. Lancet 392 , 508-520, doi:10.1016/S0140-6736(18)31129-2 (2018).

3. Baron-Cohen, S. \& Wheelwright, S. The Friendship Questionnaire: an investigation of adults with Asperger syndrome or high-functioning autism, and normal sex differences. J Autism Dev Disord 33, 509-517, doi:10.1023/a:1025879411971 (2003).

4. Bottema-Beutel, K. Glimpses into the blind spot: Social interaction and autism. J Commun Disord 68, 24-34, doi:10.1016/j.jcomdis.2017.06.008 (2017).

5. Knott, F., Dunlop, A. W. \& Mackay, T. Living with ASD: how do children and their parents assess their difficulties with social interaction and understanding? Autism 10, 609-617, doi:10.1177/1362361306068510 (2006).

6. Mackay, T., Knott, F. \& Dunlop, A. W. Developing social interaction and understanding in individuals with autism spectrum disorder: a groupwork intervention. J Intellect Dev Disabil 32, 279-290, doi:10.1080/13668250701689280 (2007).

7. Scassellati, B., Admoni, H. \& Mataric, M. Robots for use in autism research. Annu Rev Biomed Eng 14, 275-294, doi:10.1146/annurev-bioeng-071811-150036 (2012).

8. Canitano, R. New experimental treatments for core social domain in autism spectrum disorders. Front Pediatr 2, 61, doi:10.3389/fped.2014.00061 (2014).

9. Parker, K. J. et al. A randomized placebo-controlled pilot trial shows that intranasal vasopressin improves social deficits in children with autism. Sci Trans/ Med 11, doi:10.1126/scitranslmed.aau7356 (2019).

10. Singh, K. et al. Sulforaphane treatment of autism spectrum disorder (ASD). Proc Natl Acad Sci US A 111, 15550-15555, doi:10.1073/pnas.1416940111 (2014).

11. Basilico, B., Morandell, J. \& Novarino, G. Molecular mechanisms for targeted ASD treatments. Curr Opin Genet Dev 65, 126-137, doi:10.1016/j.gde.2020.06.004 (2020).

12. Ergaz, Z., Weinstein-Fudim, L. \& Ornoy, A. Genetic and non-genetic animal models for autism spectrum disorders (ASD). Reprod Toxicol 64, 116-140, doi:10.1016/j.reprotox.2016.04.024 (2016).

13. Schneider, T. \& Przewlocki, R. Behavioral alterations in rats prenatally exposed to valproic acid: animal model of autism. Neuropsychopharmacology 30, 80-89, doi:10.1038/sj.npp.1300518 (2005). 
14. Varghese, M. et al. Autism spectrum disorder: neuropathology and animal models. Acta Neuropathol 134, 537-566, doi:10.1007/s00401-017-1736-4 (2017).

15. Chomiak, T., Turner, N. \& Hu, B. What We Have Learned about Autism Spectrum Disorder from Valproic Acid. Patholog Res Int 2013, 712758, doi:10.1155/2013/712758 (2013).

16. Kataoka, S. et al. Autism-like behaviours with transient histone hyperacetylation in mice treated prenatally with valproic acid. Int J Neuropsychopharmacol 16, 91-103, doi:10.1017/S1461145711001714 (2013).

17. Codagnone, M. G., Podesta, M. F., Uccelli, N. A. \& Reines, A. Differential Local Connectivity and Neuroinflammation Profiles in the Medial Prefrontal Cortex and Hippocampus in the Valproic Acid Rat Model of Autism. Dev Neurosci 37, 215-231, doi:10.1159/000375489 (2015).

18. Chaliha, D. et al. A Systematic Review of the Valproic-Acid-Induced Rodent Model of Autism. Dev Neurosci 42, 12-48, doi:10.1159/000509109 (2020).

19. Nicolini, C. \& Fahnestock, M. The valproic acid-induced rodent model of autism. Exp Neuro/ 299, 217227, doi:10.1016/j.expneurol.2017.04.017 (2018).

20. Antshel, K. M., Zhang-James, Y., Wagner, K. E., Ledesma, A. \& Faraone, S. V. An update on the comorbidity of ADHD and ASD: a focus on clinical management. Expert Rev Neurother 16, 279-293, doi:10.1586/14737175.2016.1146591 (2016).

21. Goines, P. E. \& Ashwood, P. Cytokine dysregulation in autism spectrum disorders (ASD): possible role of the environment. Neurotoxicol Terato/36, 67-81, doi:10.1016/j.ntt.2012.07.006 (2013).

22. Jiang, H. Y. et al. Maternal infection during pregnancy and risk of autism spectrum disorders: $A$ systematic review and meta-analysis. Brain Behav Immun 58, 165-172, doi:10.1016/j.bbi.2016.06.005 (2016).

23. Lukasik, J. et al. Early Life Exposure to Antibiotics and Autism Spectrum Disorders: A Systematic Review. J Autism Dev Disord 49, 3866-3876, doi:10.1007/s10803-019-04093-y (2019).

24. State, M. W. \& Levitt, P. The conundrums of understanding genetic risks for autism spectrum disorders. Nat Neurosci 14, 1499-1506, doi:10.1038/nn.2924 (2011).

25. Tick, B., Bolton, P., Happe, F., Rutter, M. \& Rijsdijk, F. Heritability of autism spectrum disorders: a metaanalysis of twin studies. J Child Psychol Psychiatry 57, 585-595, doi:10.1111/jcpp.12499 (2016).

26. Bittker, S. S. \& Bell, K. R. Acetaminophen, antibiotics, ear infection, breastfeeding, vitamin D drops, and autism: an epidemiological study. Neuropsychiatr Dis Treat 14, 1399-1414, doi:10.2147/NDT.S158811 (2018).

27. Wimberley, T. et al. Otitis media, antibiotics, and risk of autism spectrum disorder. Autism Res 11, 14321440, doi:10.1002/aur.2015 (2018).

28. Jia, W., Li, H., Zhao, L. \& Nicholson, J. K. Gut microbiota: a potential new territory for drug targeting. Nat Rev Drug Discov 7, 123-129, doi:10.1038/nrd2505 (2008).

29. Needham, B. D., Tang, W. \& Wu, W. L. Searching for the gut microbial contributing factors to social behavior in rodent models of autism spectrum disorder. Dev Neurobio/ 78, 474-499, doi:10.1002/dneu.22581 (2018). 
30. Hoban, A. E. et al. Behavioural and neurochemical consequences of chronic gut microbiota depletion during adulthood in the rat. Neuroscience 339, 463-477, doi:10.1016/j.neuroscience.2016.10.003 (2016).

31. Ouwehand, A. C. et al. Probiotics reduce symptoms of antibiotic use in a hospital setting: a randomized dose response study. Vaccine 32, 458-463, doi:10.1016/j.vaccine.2013.11.053 (2014).

32. Foster, J. A., Lyte, M., Meyer, E. \& Cryan, J. F. Gut Microbiota and Brain Function: An Evolving Field in Neuroscience. Int J Neuropsychopharmacol 19, doi:10.1093/ijnp/pyv114 (2016).

33. Umbrello, G. \& Esposito, S. Microbiota and neurologic diseases: potential effects of probiotics. $J$ Trans/ Med 14, 298, doi:10.1186/s12967-016-1058-7 (2016).

34. Dalile, B., Van Oudenhove, L., Vervliet, B. \& Verbeke, K. The role of short-chain fatty acids in microbiotagut-brain communication. Nat Rev Gastroenterol Hepatol 16, 461-478, doi:10.1038/s41575-019-0157-3 (2019).

35. Markram, K., Rinaldi, T., La Mendola, D., Sandi, C. \& Markram, H. Abnormal fear conditioning and amygdala processing in an animal model of autism. Neuropsychopharmacology 33, 901-912, doi:10.1038/sj.npp.1301453 (2008).

36. Henbid, M. T. et al. Sociability impairments in Genetic Absence Epilepsy Rats from Strasbourg: Reversal by the T-type calcium channel antagonist Z944. Exp Neurol 296, 16-22, doi:10.1016/j.expneurol.2017.06.022 (2017).

37. Wall, R. et al. Contrasting effects of Bifidobacterium breve NCIMB 702258 and Bifidobacterium breve DPC 6330 on the composition of murine brain fatty acids and gut microbiota. Am J Clin Nutr 95, 12781287, doi:10.3945/ajcn.111.026435 (2012).

38. Desbonnet, L. et al. Gut microbiota depletion from early adolescence in mice: Implications for brain and behaviour. Brain Behav Immun 48, 165-173, doi:10.1016/j.bbi.2015.04.004 (2015).

39. Leclercq, S. et al. Low-dose penicillin in early life induces long-term changes in murine gut microbiota, brain cytokines and behavior. Nat Commun 8, 15062, doi:10.1038/ncomms15062 (2017).

40. Ternák, G. Antibiotic-modified Microbiome Might Be Responsible for Non-contagious World-wide Epidemics. American Journal of Bioscience and Bioengineering 7, 34-39, doi:10.11648/j.bio.20190702.12 (2019).

41. Bercik, P. \& Collins, S. M. The effects of inflammation, infection and antibiotics on the microbiota-gutbrain axis. Adv Exp Med Bio/ 817, 279-289, doi:10.1007/978-1-4939-0897-4_13 (2014).

42. Hall, A. C. et al. Valproate regulates GSK-3-mediated axonal remodeling and synapsin I clustering in developing neurons. Mol Cell Neurosci 20, 257-270, doi:10.1006/mcne.2002.1117 (2002).

43. Edalatmanesh, M. A., Nikfarjam, H., Vafaee, F. \& Moghadas, M. Increased hippocampal cell density and enhanced spatial memory in the valproic acid rat model of autism. Brain Res 1526, 15-25, doi:10.1016/j.brainres.2013.06.024 (2013).

44. Suez, J. et al. Post-Antibiotic Gut Mucosal Microbiome Reconstitution Is Impaired by Probiotics and Improved by Autologous FMT. Cell 174, 1406-1423 e1416, doi:10.1016/j.cell.2018.08.047 (2018). 
45. Wang, T. et al. Lactobacillus fermentum NS9 restores the antibiotic induced physiological and psychological abnormalities in rats. Benef Microbes 6, 707-717, doi:10.3920/BM2014.0177 (2015).

46. Navarro, F., Liu, Y. \& Rhoads, J. M. Can probiotics benefit children with autism spectrum disorders? World J Gastroenterol 22, 10093-10102, doi:10.3748/wjg.v22.i46.10093 (2016).

47. Niu, M. et al. Characterization of Intestinal Microbiota and Probiotics Treatment in Children With Autism Spectrum Disorders in China. Front Neuro/ 10, 1084, doi:10.3389/fneur.2019.01084 (2019).

48. Santocchi, E. et al. Gut to brain interaction in Autism Spectrum Disorders: a randomized controlled trial on the role of probiotics on clinical, biochemical and neurophysiological parameters. BMC Psychiatry 16, 183, doi:10.1186/s12888-016-0887-5 (2016).

49. Shaaban, S. Y. et al. The role of probiotics in children with autism spectrum disorder: A prospective, open-label study. Nutr Neurosci 21, 676-681, doi:10.1080/1028415X.2017.1347746 (2018).

50. de Theije, C. G. et al. Altered gut microbiota and activity in a murine model of autism spectrum disorders. Brain Behav Immun 37, 197-206, doi:10.1016/j.bbi.2013.12.005 (2014).

51. Poolchanuan, P. et al. An anticonvulsive drug, valproic acid (valproate), has effects on the biosynthesis of fatty acids and polyketides in microorganisms. Sci Rep 10, 9300, doi:10.1038/s41598-020-66251-y (2020).

52. Wang, J. P. et al. Effects of Dietary Fat Profile on Gut Microbiota in Valproate Animal Model of Autism. Front Med (Lausanne) 7, 151, doi:10.3389/fmed.2020.00151 (2020).

53. Sunand K, M. G. K., Bakshi V. Supplementation of Lactobacillus Probiotic Strains Supports Gut- BrainAxis and Defends Autistic Deficits Occurred by Valproic Acid-Induced Prenatal Model of Autism. Pharmacognosy Journal, 12, 1658-1669, doi:10.5530/pj.2020.12.226 (2020).

54. Silva, Y. P., Bernardi, A. \& Frozza, R. L. The Role of Short-Chain Fatty Acids From Gut Microbiota in GutBrain Communication. Front Endocrinol (Lausanne) 11, 25, doi:10.3389/fendo.2020.00025 (2020).

55. Smith, P. M. et al. The microbial metabolites, short-chain fatty acids, regulate colonic Treg cell homeostasis. Science 341, 569-573, doi:10.1126/science.1241165 (2013).

56. Wong, J. M., de Souza, R., Kendall, C. W., Emam, A. \& Jenkins, D. J. Colonic health: fermentation and short chain fatty acids. J Clin Gastroentero/ 40, 235-243, doi:10.1097/00004836-200603000-00015 (2006).

57. Roy, C. C., Kien, C. L., Bouthillier, L. \& Levy, E. Short-chain fatty acids: ready for prime time? Nutr Clin Pract 21, 351-366, doi:10.1177/0115426506021004351 (2006).

58. Liu, S. et al. Altered gut microbiota and short chain fatty acids in Chinese children with autism spectrum disorder. Sci Rep 9, 287, doi:10.1038/s41598-018-36430-z (2019).

59. Wang, J. et al. Fecal Short-Chain Fatty Acids Levels Were Not Associated With Autism Spectrum Disorders in Chinese Children: A Case-Control Study. Front Neurosci 13, 1216, doi:10.3389/fnins.2019.01216 (2019).

60. Wang, L. et al. Elevated fecal short chain fatty acid and ammonia concentrations in children with autism spectrum disorder. Dig Dis Sci 57, 2096-2102, doi:10.1007/s10620-012-2167-7 (2012). 
61. MacFabe, D. F. Enteric short-chain fatty acids: microbial messengers of metabolism, mitochondria, and mind: implications in autism spectrum disorders. Microb Ecol Health Dis 26, 28177, doi:10.3402/mehd.v26.28177 (2015).

62. Becattini, S., Taur, Y. \& Pamer, E. G. Antibiotic-Induced Changes in the Intestinal Microbiota and Disease. Trends Mol Med 22, 458-478, doi:10.1016/j.molmed.2016.04.003 (2016).

63. Deckmann, I., Schwingel, G. B., Fontes-Dutra, M., Bambini-Junior, V. \& Gottfried, C. Neuroimmune Alterations in Autism: A Translational Analysis Focusing on the Animal Model of Autism Induced by Prenatal Exposure to Valproic Acid. Neuroimmunomodulation 25, 285-299, doi:10.1159/000492113 (2018).

64. Grasa, L. et al. Antibiotic-Induced Depletion of Murine Microbiota Induces Mild Inflammation and Changes in Toll-Like Receptor Patterns and Intestinal Motility. Microb Ecol 70, 835-848, doi:10.1007/s00248-015-0613-8 (2015).

65. Sun, L. et al. Antibiotic-Induced Disruption of Gut Microbiota Alters Local Metabolomes and Immune Responses. Front Cell Infect Microbio/ 9, 99, doi:10.3389/fcimb.2019.00099 (2019).

66. de Theije, C. G. et al. Intestinal inflammation in a murine model of autism spectrum disorders. Brain Behav Immun 37, 240-247, doi:10.1016/j.bbi.2013.12.004 (2014).

67. Dufour-Rainfray, D. et al. Behavior and serotonergic disorders in rats exposed prenatally to valproate: a model for autism. Neurosci Lett 470, 55-59, doi:10.1016/j.neulet.2009.12.054 (2010).

68. Lucchina, L. \& Depino, A. M. Altered peripheral and central inflammatory responses in a mouse model of autism. Autism Res 7, 273-289, doi:10.1002/aur.1338 (2014).

69. Corridoni, D. et al. Probiotic bacteria regulate intestinal epithelial permeability in experimental ileitis by a TNF-dependent mechanism. PLoS One 7, e42067, doi:10.1371/journal.pone.0042067 (2012).

70. Leber, B. et al. The influence of probiotic supplementation on gut permeability in patients with metabolic syndrome: an open label, randomized pilot study. Eur J Clin Nutr 66, 1110-1115, doi:10.1038/ejcn.2012.103 (2012).

71. Lyte, J. M. et al. Gut-brain axis serotonergic responses to acute stress exposure are microbiomedependent. Neurogastroenterol Motil 32, e13881, doi:10.1111/nmo.13881 (2020).

72. O'Mahony, S. M., Clarke, G., Borre, Y. E., Dinan, T. G. \& Cryan, J. F. Serotonin, tryptophan metabolism and the brain-gut-microbiome axis. Behav Brain Res 277, 32-48, doi:10.1016/j.bbr.2014.07.027 (2015).

73. Ruiz, L., Delgado, S., Ruas-Madiedo, P., Sanchez, B. \& Margolles, A. Bifidobacteria and Their Molecular Communication with the Immune System. Front Microbio/ 8, 2345, doi:10.3389/fmicb.2017.02345 (2017).

74. Kennedy, P. J., Cryan, J. F., Dinan, T. G. \& Clarke, G. Kynurenine pathway metabolism and the microbiotagut-brain axis. Neuropharmacology 112, 399-412, doi:10.1016/j.neuropharm.2016.07.002 (2017).

75. Maqsood, R. \& Stone, T. W. The Gut-Brain Axis, BDNF, NMDA and CNS Disorders. Neurochem Res 41, 2819-2835, doi:10.1007/s11064-016-2039-1 (2016).

76. Frohlich, E. E. et al. Cognitive impairment by antibiotic-induced gut dysbiosis: Analysis of gut microbiota-brain communication. Brain Behav Immun 56, 140-155, doi:10.1016/j.bbi.2016.02.020 
(2016).

77. Kang, J. \& Kim, E. Suppression of NMDA receptor function in mice prenatally exposed to valproic acid improves social deficits and repetitive behaviors. Front Mol Neurosci 8, 17, doi:10.3389/fnmol.2015.00017 (2015).

78. Kuo, H. Y. \& Liu, F. C. Molecular Pathology and Pharmacological Treatment of Autism Spectrum Disorder-Like Phenotypes Using Rodent Models. Front Cell Neurosci 12, 422, doi:10.3389/fncel.2018.00422 (2018).

79. Finlay, J. M. et al. Effects of prefrontal cortex and hippocampal NMDA NR1-subunit deletion on complex cognitive and social behaviors. Brain Res 1600, 70-83, doi:10.1016/j.brainres.2014.10.037 (2015).

80. Yuen, E. Y. et al. Serotonin 5-HT1A receptors regulate NMDA receptor channels through a microtubuledependent mechanism. J Neurosci 25, 5488-5501, doi:10.1523/JNEUROSCI.1187-05.2005 (2005).

\section{Tables}

Table 1. Three chamber social interaction test. ABx: broad-spectrum antibiotics treated group, $A B x+p r o b i o t i c:$ broad-spectrum antibiotics- and probiotic treated group, Probiotic: probiotic treated group, P-VPA: valproic acid and probiotic treated group, C-VPA: valproic acid treated group, Control: control group. Values of the stranger cage latency, the empty cage latency and sociability index are median (IQR) and the total distance moved values, number of raring behavior and number of grooming behavior are means and SEMs. One-way ANOVA, Kruskal-Wallis test and Mann-Whitney U-test. Between the groups significances $(p<0.05)$ are represented by distinct (a-h) lowercase letters. 


\begin{tabular}{|c|c|c|c|c|c|c|}
\hline $\begin{array}{l}3 \text { chamber } \\
\text { social } \\
\text { interaction } \\
\text { test }\end{array}$ & $\underset{n=10}{A B x}$ & ABx+probiotic $n=10$ & probiotic $n=10$ & $\begin{array}{c}\text { P-VPA } \\
n=10\end{array}$ & $\begin{array}{r}\text { C-VPA } \\
n=10\end{array}$ & $\begin{array}{c}\text { Control } \\
n=10\end{array}$ \\
\hline $\begin{array}{l}\text { Stranger cage } \\
\text { latency (sec) }\end{array}$ & $\begin{array}{c}17.50 \\
(9.25- \\
37.00)\end{array}$ & $\begin{array}{l}19.00 \\
(7.50-63.00)\end{array}$ & $\begin{array}{l}8.50 \\
(4.00-24.50)\end{array}$ & $\begin{array}{l}6.00 \\
(4.00- \\
10.25)\end{array}$ & $\begin{array}{l}3.00 \\
(1.50- \\
72.75)\end{array}$ & $\begin{array}{l}19.00 \\
(5.25- \\
30.00)\end{array}$ \\
\hline $\begin{array}{l}\text { Empty cage } \\
\text { latency (sec) }\end{array}$ & $\begin{array}{l}3.50 \\
(3.00- \\
10.50)\end{array}$ & $\begin{array}{l}25.00 \\
(2.50-80.00)\end{array}$ & $\begin{array}{r}146.00 \\
(58.75- \\
189.50)\end{array}$ & $\begin{array}{l}5.00 \\
(2.25- \\
219.50)\end{array}$ & $\begin{array}{c}36.00 \\
(3.50- \\
60.00)\end{array}$ & $\begin{array}{l}7.00 \\
(3.00- \\
76.50)\end{array}$ \\
\hline $\begin{array}{l}\text { Sociability } \\
\text { index }\end{array}$ & $\begin{array}{l}-0.40 \\
(-0.58- \\
0.05) \\
\text { abcd }\end{array}$ & $\begin{array}{l}0.76 \\
(0.61-0.85)^{\mathrm{ae}}\end{array}$ & $\begin{array}{l}0.42 \\
(0.33-0.58)^{b f}\end{array}$ & $\begin{array}{l}0.77 \\
(0.49- \\
0.86)^{\mathrm{cg}}\end{array}$ & $\begin{array}{l}-0.27 \\
(-0.68- \\
0.16)^{\text {efgh }}\end{array}$ & $\begin{array}{l}0.65 \\
(0.35- \\
0.75)^{\text {dh }}\end{array}$ \\
\hline $\begin{array}{l}\text { Total distance } \\
\text { moved }(\mathrm{cm})\end{array}$ & $\begin{array}{l}2318.36 \\
\pm 298.76\end{array}$ & $\begin{array}{c}2629.43 \\
\pm 165.48\end{array}$ & $\begin{array}{l}2859.49 \\
\pm 506.73\end{array}$ & $\begin{array}{c}2153.00 \\
\pm \\
106.36\end{array}$ & $\begin{array}{r}1974.25 \\
\pm 99.73\end{array}$ & $\begin{array}{c}2754.44 \\
\pm \\
249.01\end{array}$ \\
\hline $\begin{array}{l}\text { No. of rearing } \\
\text { behavior }\end{array}$ & $\begin{array}{l}15.20 \\
\pm 7.79\end{array}$ & $\begin{array}{l}17.10 \\
\pm 8.28\end{array}$ & $\begin{array}{l}16.20 \\
\pm 8.20\end{array}$ & $\begin{array}{l}17.60 \\
\pm 9.79\end{array}$ & $\begin{array}{l}13.70 \\
\pm 9.84\end{array}$ & $\begin{array}{l}17.70 \\
\pm 8.43\end{array}$ \\
\hline $\begin{array}{l}\text { No. of } \\
\text { grooming } \\
\text { behavior }\end{array}$ & $\begin{array}{l}0.90 \\
\pm 1.73\end{array}$ & $\begin{array}{l}5.10 \\
\pm 2.69\end{array}$ & $\begin{array}{l}3.60 \\
\pm 3.37\end{array}$ & $\begin{array}{l}5.70 \\
\pm 6.12\end{array}$ & $\begin{array}{l}3.10 \\
\pm 2.91\end{array}$ & $\begin{array}{l}7.10 \\
\pm 5.20\end{array}$ \\
\hline
\end{tabular}

Table 2. Analysis of the short chain fatty acids (acetic acid, propionic acid and butyric acid) concentrations $(100 \mathrm{mg} / \mathrm{mmol} / \mathrm{l})$ in the faecal samples before and after the treatments. ABx: broad-spectrum antibiotics treated group, $A B x+$ probiotic: broad-spectrum antibiotics- and probiotic treated group, Probiotic: probiotic treated group, P-VPA: valproic acid and probiotic treated group, C-VPA: valproic acid treated group, Control: control group. Values of the concentrations are median (IQR). Kruskal-Wallis test, Mann-Whitney U-test and Friedman test. Between the groups significances $(p<0.05)$ are represented by distinct $(a-e)$ lowercase letters. 


\begin{tabular}{|c|c|c|c|c|c|c|}
\hline $\begin{array}{l}\text { SCFA } \\
\text { concentrations } \\
(100 \mathrm{mg} / \mathrm{mmol} / \mathrm{l})\end{array}$ & $\underset{n=10}{A B x}$ & $A B x+$ probiotic $n=10$ & probiotic $n=10$ & $\begin{array}{l}\text { P-VPA } \\
n=10\end{array}$ & $\begin{array}{r}\text { C-VPA } \\
\mathrm{n}=10\end{array}$ & $\begin{array}{c}\text { Control } \\
n=10\end{array}$ \\
\hline \multicolumn{7}{|l|}{ Before treatments } \\
\hline acetic acid & $\begin{array}{l}5.61 \\
(3.71- \\
6.97)\end{array}$ & $\begin{array}{l}4.04 \\
(2.65-7.09)\end{array}$ & $\begin{array}{l}5.20 \\
(3.06-5.90)\end{array}$ & $\begin{array}{l}8.79 \\
(7.13- \\
9.75)\end{array}$ & $\begin{array}{l}6.84 \\
(5.89- \\
7.78)\end{array}$ & $\begin{array}{l}6.94 \\
(3.74- \\
7.60)\end{array}$ \\
\hline propionic acid & $\begin{array}{l}1.88 \\
(1.64- \\
2.61)\end{array}$ & $\begin{array}{l}1.59 \\
(1.28-2.30)\end{array}$ & $\begin{array}{l}1.77 \\
(1.34-2.48)\end{array}$ & $\begin{array}{l}3.11 \\
(2.82- \\
4.16)\end{array}$ & $\begin{array}{l}2.37 \\
(2.17- \\
2.75)\end{array}$ & $\begin{array}{l}1.80 \\
(1.60- \\
2.91)\end{array}$ \\
\hline butyric acid & $\begin{array}{l}1.23 \\
(1.12- \\
1.34)\end{array}$ & $\begin{array}{l}0.98 \\
(0.93-1.10)\end{array}$ & $\begin{array}{l}0.96 \\
(0.81-1.12)\end{array}$ & $\begin{array}{l}1.70 \\
(1.35- \\
2.53)\end{array}$ & $\begin{array}{l}1.45 \\
(1.10- \\
1.98)\end{array}$ & $\begin{array}{l}1.06 \\
(0.98- \\
1.44)\end{array}$ \\
\hline total & $\begin{array}{l}8.72 \\
(6.21- \\
10.60)\end{array}$ & $\begin{array}{l}6.14 \\
(5.26-10.37)\end{array}$ & $\begin{array}{l}7.69 \\
(5.31-9.22)\end{array}$ & $\begin{array}{l}13.64 \\
(10.90- \\
16.55)\end{array}$ & $\begin{array}{c}10.86 \\
(9.31- \\
12.40)\end{array}$ & $\begin{array}{c}10.35 \\
(6.39- \\
11.64)\end{array}$ \\
\hline \multicolumn{7}{|l|}{ After treatments } \\
\hline acetic acid & $\begin{array}{l}0.00 \\
(0- \\
2.90)^{\text {abcde }}\end{array}$ & $\begin{array}{l}3.03 \\
(2.31-4.96)^{a}\end{array}$ & $\begin{array}{l}4.16 \\
(2.19-7.20)^{b}\end{array}$ & $\begin{array}{l}5.93 \\
(4.49- \\
9.34)^{\mathrm{c}}\end{array}$ & $\begin{array}{l}7.77 \\
(6.41- \\
8.77)^{d}\end{array}$ & $\begin{array}{l}4.40 \\
(3.01- \\
5.00)^{\mathrm{e}}\end{array}$ \\
\hline propionic acid & $\begin{array}{l}0.00 \\
(0.00- \\
1.02)^{\text {abcde }}\end{array}$ & $\begin{array}{l}0.96 \\
(0.67-1.54)^{a}\end{array}$ & $\begin{array}{l}2.36 \\
(1.49-2.69)^{b}\end{array}$ & $\begin{array}{l}2.81 \\
\left(1.98^{-}\right. \\
3.80)^{\mathrm{c}}\end{array}$ & $\begin{array}{l}2.93 \\
(2.66- \\
3.87)^{d}\end{array}$ & $\begin{array}{l}1.84 \\
(1.54- \\
2.34)^{\mathrm{e}}\end{array}$ \\
\hline butyric acid & $\begin{array}{l}0.00 \\
(0.00- \\
0.54)^{\text {abcde }}\end{array}$ & $\begin{array}{l}1.30 \\
(0.96-1.49)^{a}\end{array}$ & $\begin{array}{l}1.04 \\
(0.83-1.33)^{b}\end{array}$ & $\begin{array}{l}1.16 \\
(0.93- \\
2.39)^{c}\end{array}$ & $\begin{array}{l}2.23 \\
(1.79- \\
2.33)^{d}\end{array}$ & $\begin{array}{l}1.30 \\
(0.96- \\
1.35)^{\mathrm{e}}\end{array}$ \\
\hline total & $\begin{array}{l}0.00 \\
(0.00- \\
4.44)^{\text {abcde }}\end{array}$ & $\begin{array}{l}4.89 \\
(3.97-7.55)^{a}\end{array}$ & $\begin{array}{l}7.34 \\
(4.80-10.67)^{b}\end{array}$ & $\begin{array}{l}10.66 \\
(7.69- \\
15.03)^{c}\end{array}$ & $\begin{array}{l}13.30 \\
(11.11- \\
15.14)^{d}\end{array}$ & $\begin{array}{l}7.48 \\
(5.66- \\
8.11)^{\mathrm{e}}\end{array}$ \\
\hline
\end{tabular}

\section{Figures}




\section{Probiotic}

P-VPA

C-VPA

Control

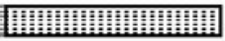

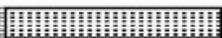

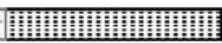

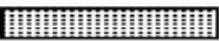

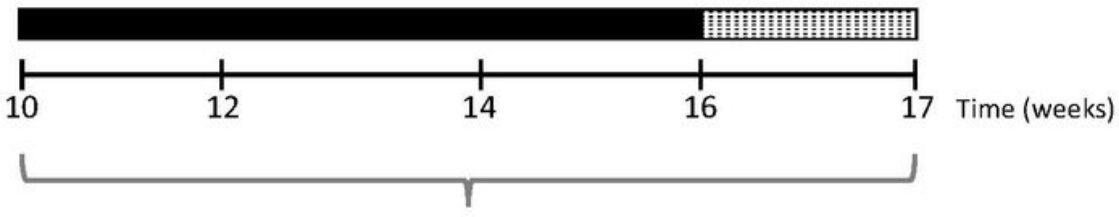

Examination of short chain fatty acids composition [inill Behavioral tests

Valproic acid treatment

No treatments

\section{Figure 1}

Experimental arrangement of the treatments. Experimental treatments for the groups including demonstration of time and duration of antibiotics and probiotic treatments and those of behavioral testing. $A B x$ : broad-spectrum antibiotics treated group, $A B x+$ probiotic: broad-spectrum antibiotics- and probiotic treated group, Probiotic: probiotic treated group, P-VPA: valproic acid and probiotic treated group, C-VPA: valproic acid treated group, Control: control group without any treatment. 


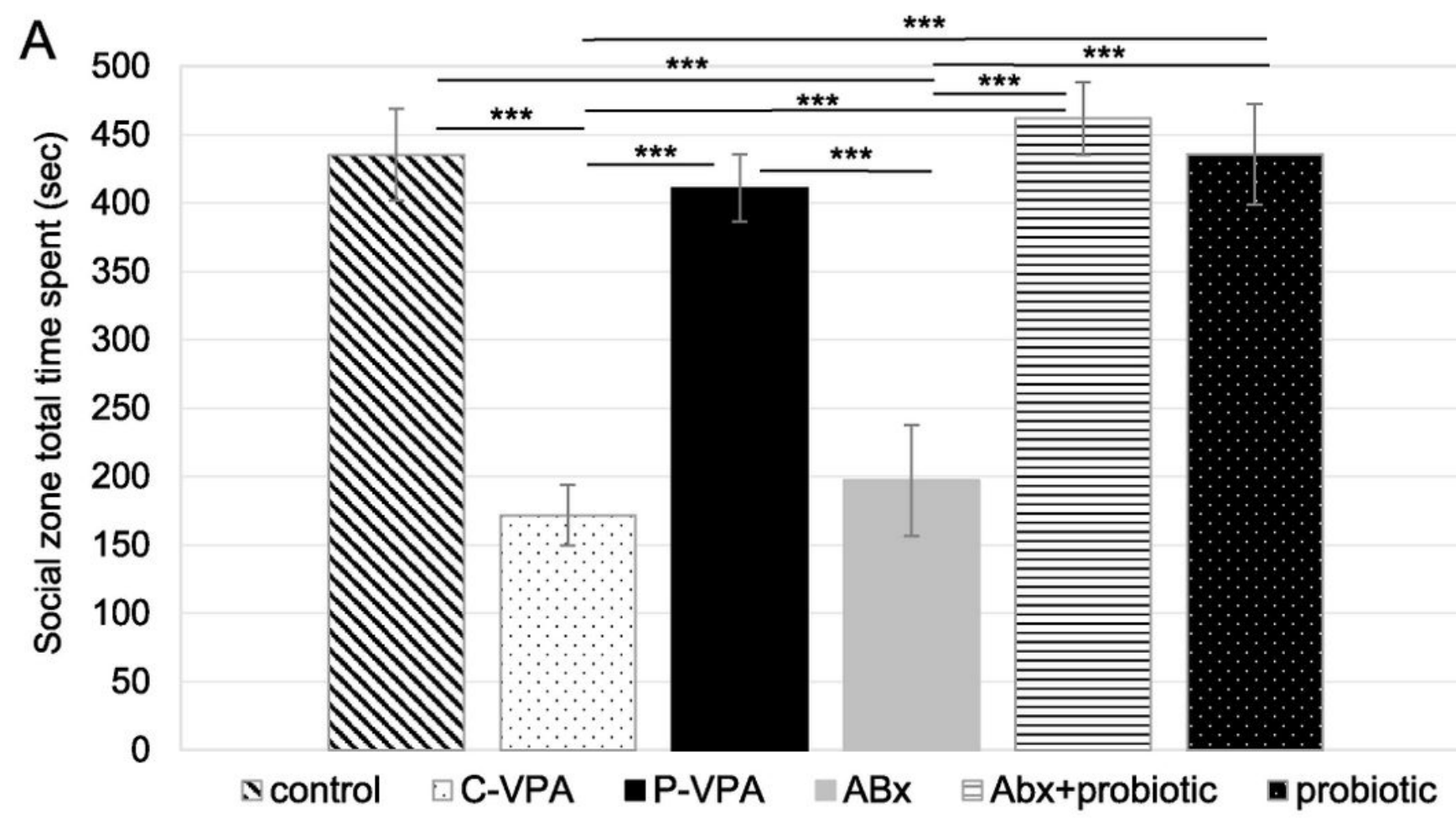

$\mathrm{B}$

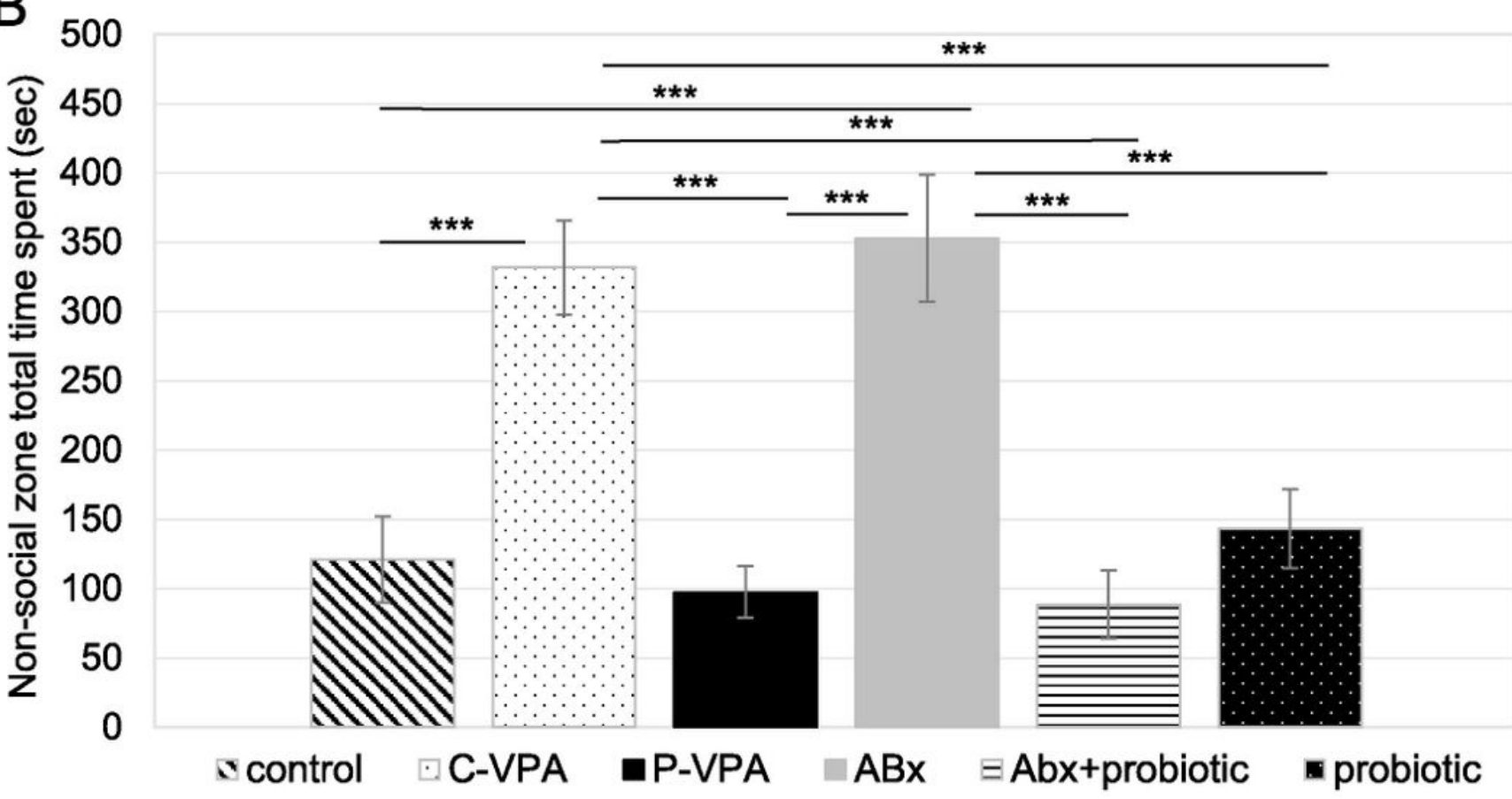

Figure 2

Time spent with the Social- (A) and non-social (B) zone exploration (sec) in the three chamber social interaction test. Control: control group; C-VPA: valproic acid treated group; P-VPA: valproic acid and probiotic treated group; $A B x$ : broad-spectrum antibiotics treated group, $A B x+$ probiotic: broad-spectrum antibiotics- and probiotic treated group, probiotic: probiotic treated group. One-way ANOVA ( $* \star \star p<0.001)$. Data graphed as mean \pm SEM. 

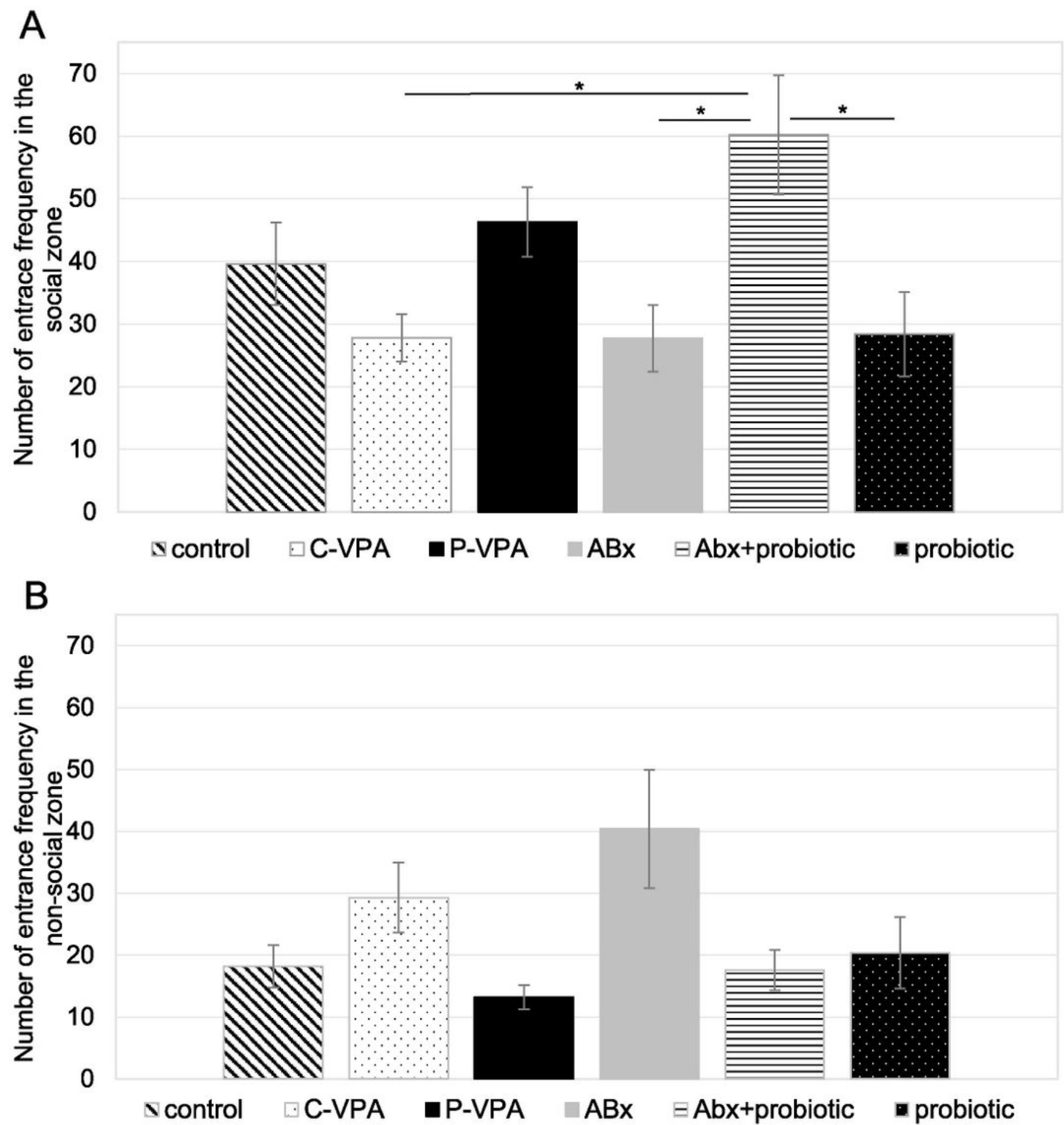

Figure 3

Frequency with the Social- $(A)$ and non-social (B) zone exploration in the three chamber social interaction test; Control: control group; C-VPA: valproic acid treated group; P-VPA: valproic acid and probiotic treated group; $A B x$ : broad-spectrum antibiotics treated group, $A B x+$ probiotic: broad-spectrum antibiotics- and 
probiotic treated group, probiotic: probiotic treated group. One-way ANOVA (* $p<0.05)$. Data graphed as mean \pm SEM.
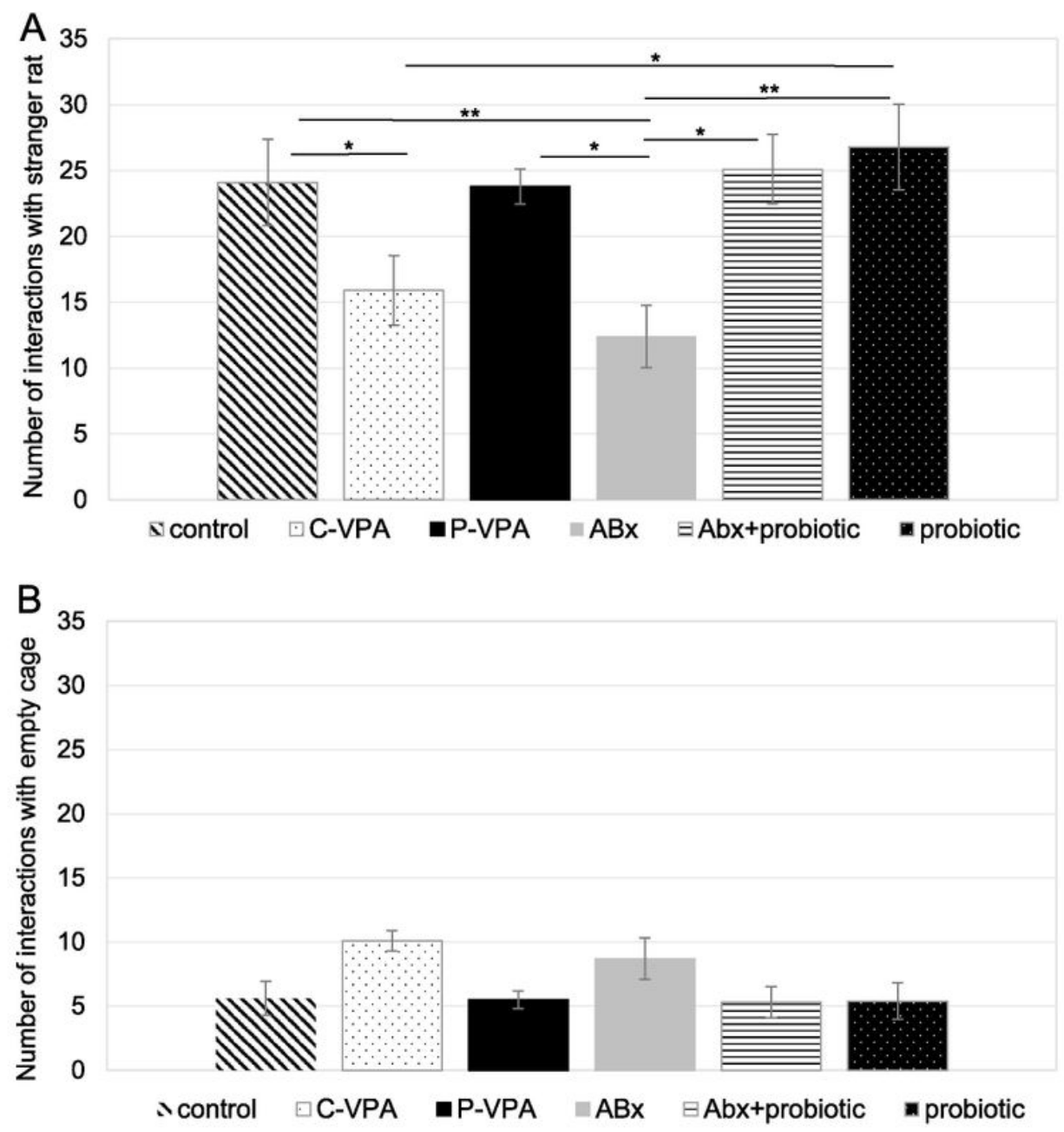

Figure 4

Number of interactions with the stranger rat $(A)$ and empty cage $(B)$ in the three chamber social interaction test; Control: control group; C-VPA: valproic acid treated group; P-VPA: valproic acid and probiotic treated 
group; $A B x$ : broad-spectrum antibiotics treated group, $A B x+$ probiotic: broad-spectrum antibiotics- and probiotic treated group, probiotic: probiotic treated group. One-way ANOVA ( $p<0.05 ; * \star p<0.01)$. Data graphed as mean \pm SEM.
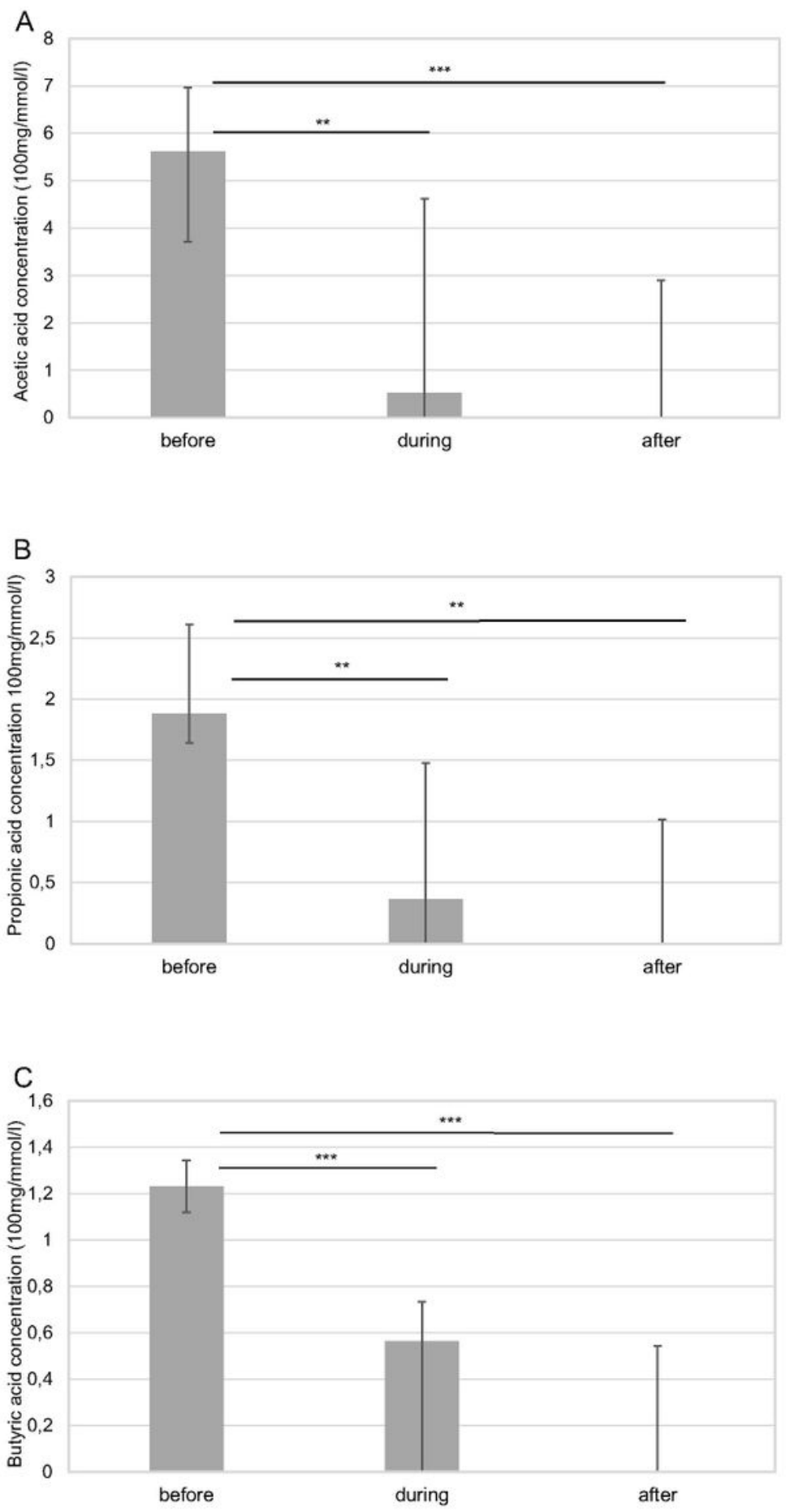

Figure 5 
The effect of antibiotics treatments on the acetic acid (A), propionic acid (B) and butyric acid (C) concentrations $(100 \mathrm{mg} / \mathrm{mmol} / \mathrm{l})$ in the faecal samples before-, during- and after the antibiotics treatment. Abx: broad-spectrum antibiotics treated group; Friedman test $(* \star p<0.01 ; * \star \star p<0.001)$. Data graphed as median \pm IQR.
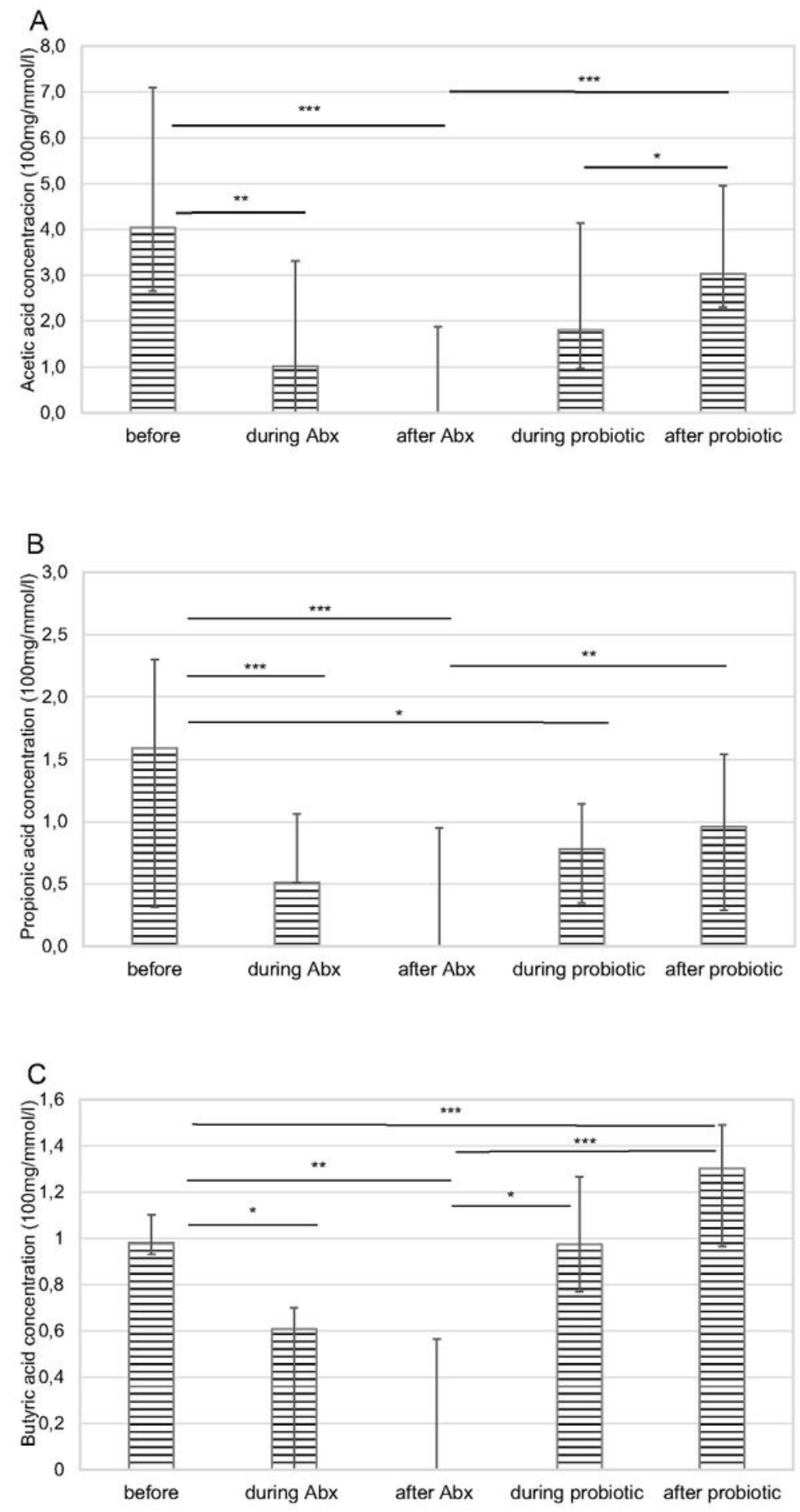

Figure 6 
The effect of antibiotics and probiotic treatments on the acetic acid (A), propionic acid (B) and butyric acid (C) concentrations $(100 \mathrm{mg} / \mathrm{mmol} / \mathrm{l})$ in the faecal samples before the treatments, during- and after the antibiotics treatment, as well as during- and after the probiotic treatment. Abx+probiotic: broad-spectrum antibiotics treated and after probiotic treated group; Friedman test $\left({ }^{*} p<0.05 ; * \star p<0.01 ; * \star \star ~ p<0.001\right)$. Data graphed as median \pm IQR.

\section{Supplementary Files}

This is a list of supplementary files associated with this preprint. Click to download.

- MintIKittiSupplementaryinformation20220106.pdf

- Supplementarydatasets.xlsx 